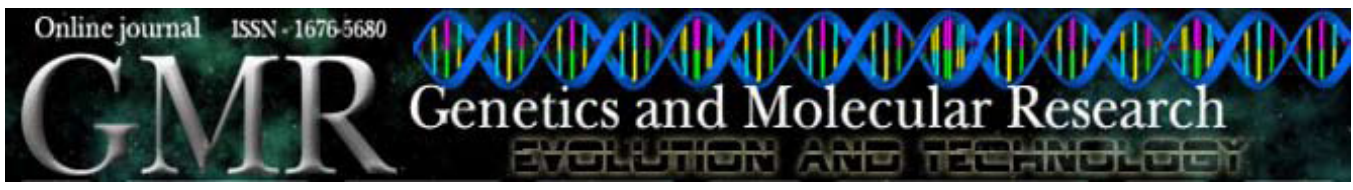

\title{
Meiotic behavior as a selection tool in silage corn breeding
}

\author{
V.F. Souza ${ }^{1}$, M.S. Pagliarini ${ }^{1}$, C.A. Scapim ${ }^{2}$, M. Rodovalho ${ }^{2}$ and M.V. Faria ${ }^{3}$ \\ ${ }^{1}$ Departamento de Biologia Celular e Genética, Universidade Estadual de Maringá, \\ Maringá, PR, Brasil \\ ${ }^{2}$ Departamento de Agronomia, Universidade Estadual de Maringá, \\ Maringá, PR, Brasil \\ ${ }^{3}$ Departamento de Agronomia, Universidade do Centro-Oeste do Paraná, \\ Guarapuava, PR, Brasil
}

Corresponding author: M.S. Pagliarini

E-mail: mspagliarini@uem.br

Genet. Mol. Res. 9 (4): 2096-2103 (2010)

Received May 22, 2010

Accepted July 27, 2010

Published October 19, 2010

DOI 10.4238/vo19-4gmr924

\begin{abstract}
In breeding programs, commercial hybrids are frequently used as a source of inbred lines to obtain new hybrids. Considering that maize production is dependent on viable gametes, the selection of populations to obtain inbred lines with high meiotic stability could contribute to the formation of new silage corn hybrids adapted to specific region. We evaluated the meiotic stability of five commercial hybrids of silage corn used in southern Brazil with conventional squashing methods. All of them showed meiotic abnormalities. Some abnormalities, such as abnormal chromosome segregation and absence of cytokinesis, occurred in all the genotypes, while others, including cytomixis and abnormal spindle orientation, were found only in some genotypes. The hybrid SG6010 had the lowest mean frequency of abnormal cells (21.27\%); the highest frequency was found in the hybrid P30K64 (44.43\%). However, the frequency of abnormal meiotic products was much lower in most genotypes, ranging from $7.63 \%$ in the hybrid CD304 to $43.86 \%$ in Garra. Taking into account the percentage of abnormal meiotic products and, hence, meiotic stability, only the hybrids CD304, P30K64, SG6010, and $\mathrm{P} 30 \mathrm{~F} 53$ are recommended to be retained in the breeding program to obtain inbred lines to create new hybrids.
\end{abstract}

Key words: Silage corn; Meiosis; Hybrids; Breeding 


\section{INTRODUCTION}

Corn is recommended as the more interesting crop for ensiling in Brazil due to its agronomic characteristics and nutritive values, besides the acceptance by cattle, buffaloes, goats, and sheep. It is also used successfully for milk production and satisfactory weaning weight in beef cattle. The utilization of maize as silage drastically reduces the costs of cattle production, mainly in the periods of scarcity of natural pastures (Zago, 1991). However, the silage maize cultivars in use in Brazil do not always show interesting characteristics for silage, a factor that creates new opportunities for breeding to exploit genetic variability for this purpose.

The choice of a silage maize cultivar is based on several agronomic characteristics, including seed production and dry matter (Gomes et al., 2004). The success of a silage maize cultivar is not only dependent on the grain production, as high production of healthy seeds is also desirable. Seed production, on the other hand, is dependent on viable gametes, which in turn are dependent on meiotic stability. Meiosis is a process controlled by a complex genetic system (Gottschalk and Kaul, 1974; Baker et al., 1976; Golubovskaya, 1979, 1989; Golubovskaya et al., 1993). High meiotic stability has been shown to depend on heterozygosis, and thus, hybrids always show less meiotic abnormalities than do inbred lines (Pagliarini, 1983; Defani-Scoarize et al., 1995a,b, 1996; Pagliarini et al., 2002). Correlation between meiotic abnormalities and combining ability in inbred lines of maize was reported by Pagliarini (1989). High combining ability, on the other hand, depends on several agronomic traits including the frequency of favorable genes and also on viable and genetically balanced gametes.

In the extensive areas of tillage in Brazil, there are no adapted cultivars of silage corn for each region. This lack justifies a breeding program to develop cultivars adapted to the edaphoclimatic conditions of the South region, where winter is harsh and large amounts of silage are required. In a breeding program, it is very common to utilize hybrids to obtain inbred lines to create a new hybrid because they were previously selected for several agronomic traits. Therefore, the meiotic stability of six commercial hybrids of silage corn was evaluated by conventional methods to select the more stable ones to obtain inbred lines.

\section{MATERIAL AND METHODS}

Five commercial hybrids of silage corn of different origins were selected to initiate the breeding program: 1. Garra (triple hybrid, Syngenta Seeds); 2. CD304 (triple hybrid, Coodetec); 3. SG6010 (single hybrid, Guerra Seeds); 4. P30K64 (single hybrid, DuPont, Brazil); 5. P30F35 (single hybrid, DuPont, Brazil). For meiotic analyses, the hybrids were cultivated on the Experimental Farm of the State University of Maringá, in the summer of 2008.

For meiotic studies, inflorescences were collected and fixed in a mixture of $95 \%$ ethanol and acetic acid (3:1) for $24 \mathrm{~h}$, transferred to $70 \%$ alcohol and stored under refrigeration until use. Microsporocytes were prepared by squashing and staining with $1 \%$ propionic carmine. Meiotic abnormalities were observed in each phase of microsporogenesis. Photomicrographs were made with a Wild Leitz microscope using Kodak Imagelink - HQ, ISO 25 black and white film.

\section{RESULTS AND DISCUSSION}

Microsporogenesis analysis showed that irregular chromosome segregation and absence of cytokinesis occurred in all five silage corn hybrids, but cytomixis and abnormalities in the spindle formation were recorded only in some hybrids. The number of cells analyzed per meiotic phase and the percentage of cells affected by each abnormality are presented in Table 1 . The lowest frequency of meiotic abnormality was found in the hybrid SG6010 (21.3\%), and the highest, in the hybrid P30K64 (44.4\%). 


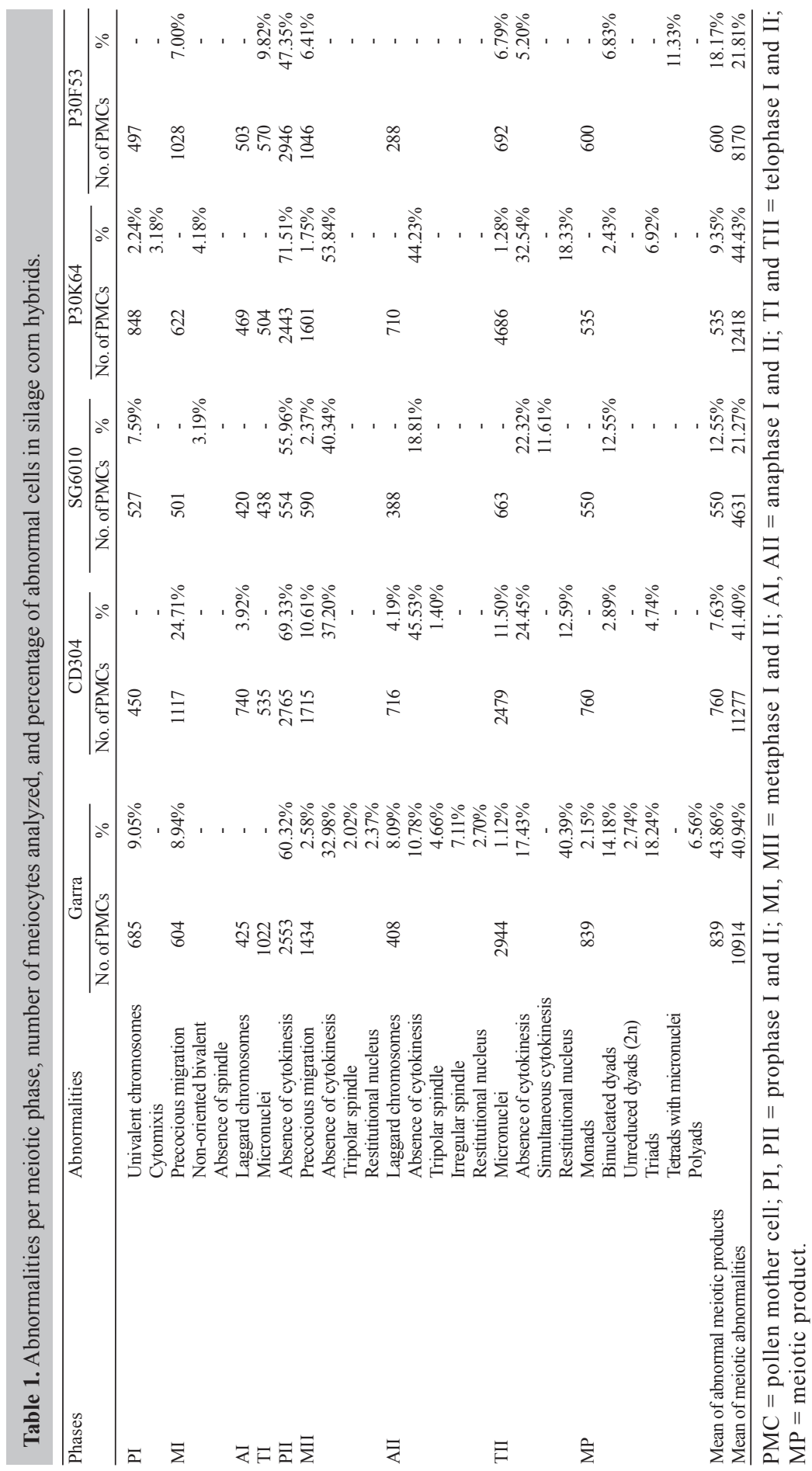


Univalent chromosomes in diakinesis (Figure 1a) were recorded in four hybrids. Such chromosomes and those resulting from precocious chiasma terminalization migrated precociously to the poles in metaphase I (Figure 1b); however, those chromosomes with late chiasma terminalization behaved as laggards in anaphase I (Figure 1d). Non-oriented bivalents at the metaphase plate (Figure 1c) were also recorded in the hybrids SG6010 and P30K64. The chromosomes with irregular segregation in metaphase I and anaphase I, in general, reached the poles in time to be included in the nucleus. Only a few micronuclei (Figure 1e) were found in telophase I. Irregular chromosome segregation (Figure 1f), leading to micronucleus formation, was also recorded in the second division, generating unbalanced gametes, but in low frequency. Irregular chromosome segregation is the most common meiotic abnormality reported among inbred lines and maize hybrids (Pagliarini, 1983, 1989; Defani-Scoarize et al., 1995a,b, 1996; Caetano-Pereira et al., 1998; Utsunomiya et al., 2002; Pagliarini et al., 2002; Ricci et al., 2007; Silva et al., 2007).

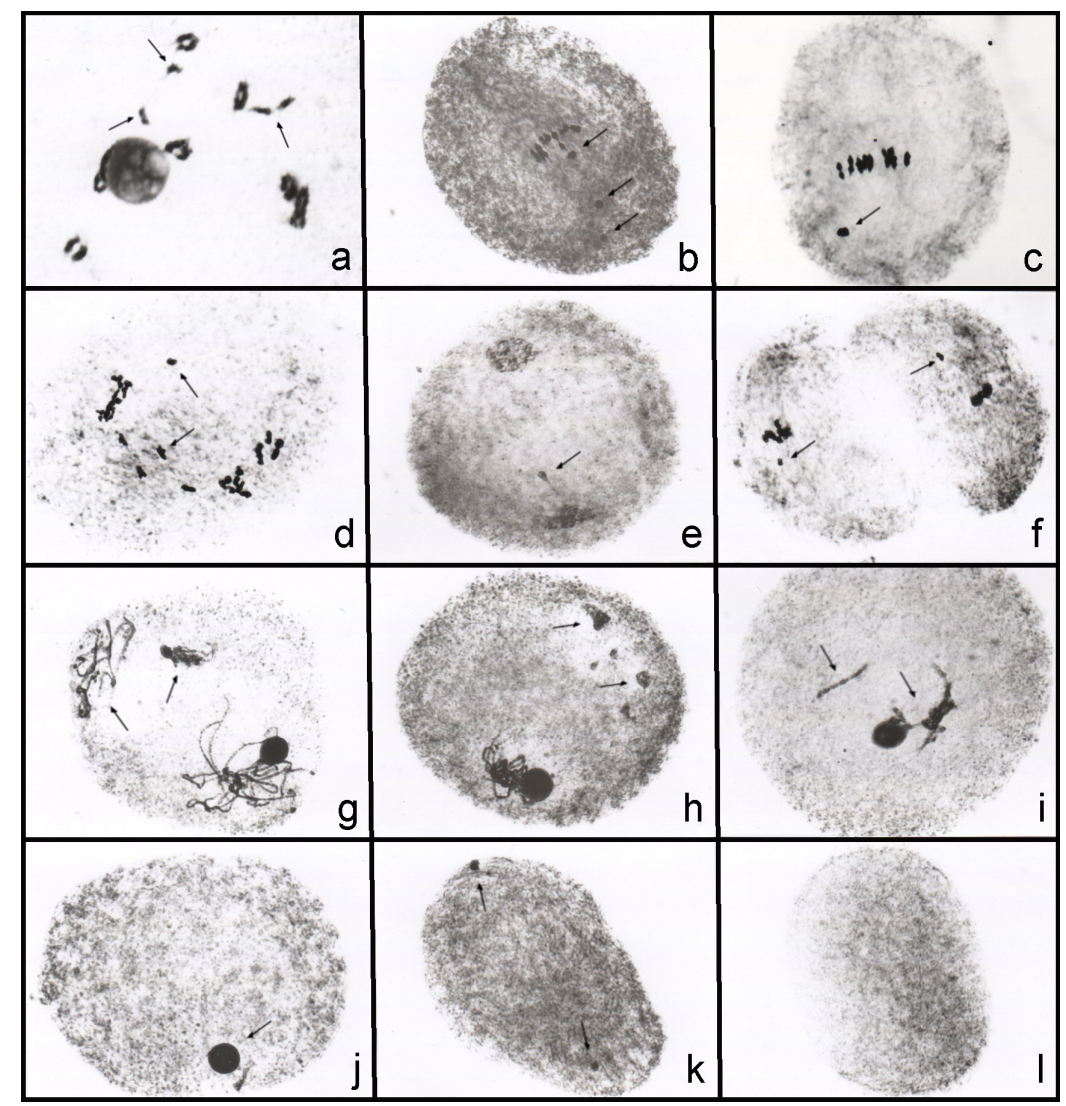

Figure 1. Irregular chromosome segregation (a-f) and cytomixis (g-1). a. Microsporocytes in diakinesis with two pairs of univalent chromosomes (arrows). b. Metaphase I with three chromosomes migrating precociously to the pole (arrows). c. A non-oriented bivalent in metaphase I (arrow). d. Laggard chromosomes in anaphase I (arrows). e. Telophase I with micronucleus (arrow). f. Metaphase II with precocious chromosome migration in both cells (arrows). g, h. Diplotene with extra chromosomes (arrows). i, j. Diplotene with chromosome loss (arrows). k. Meiocyte with only two chromosomes (arrows). l. Meiocyte without chromosomes. 
Chromosome transfer among meiocytes (cytomixis) (Figure 1g-1) was recorded in some plants of the hybrid P30K64, affecting 3.2\% of the cells. Meiocytes in prophase I with additional chromosomes (Figure 1 $\mathrm{g}, \mathrm{h}$ ) and chromosome loss (Figure 1i,j) were observed. In some meiocytes, such as those represented in Figure $1 \mathrm{j}$ and k, only a few chromosomes remained inside the cell, while in others, chromosomes were completely absent (Figure 11). Cytomixis is a phenomenon widely reported among higher plants, including maize (CaetanoPereira and Pagliarini, 1997; Utsunomiya et al., 2002). The formation of hypoploid and hyperploid cells compromises pollen viability.

The absence of the first, the second or both cytokinesis events (Figure 2) was recorded at high frequency in all the hybrids analyzed, although it was more frequent after telophase I, generating secondary meiocytes with genomes sharing the same cytoplasm (Figure 2a-c). When both cytokinesis events failed to occur, a tetranucleated monad was formed (Figure 2d), and when only one cytokinesis occurred after telophase II (Figure 2e), a binucleated dyad was formed, giving rise to two binucleated microspores (Figure 2f). Triads (Figure 2g) resulting from the absence of the second cytokinesis in one secondary meiocyte were also recorded among meiotic products. Although the percentage of meiocytes affected by the absence of the first cytokinesis was high among the hybrids analyzed, the percentages of monads, dyads, and triads were low, or sometimes zero in some hybrids, because in the majority of meiocytes a simultaneous cytokinesis occurred after telophase II giving rise to normal tetrads (Figure 2h,i).

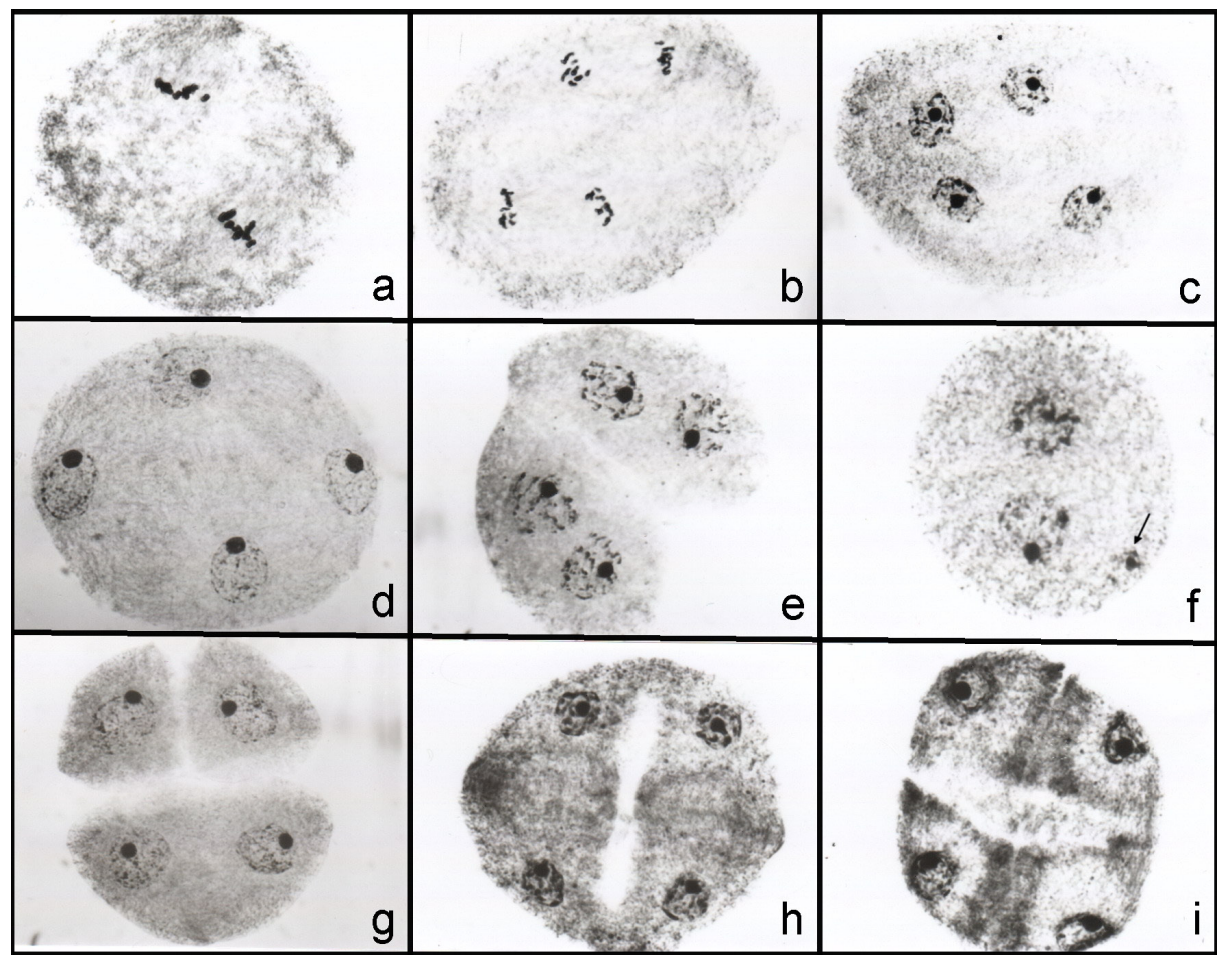

Figure 2. Some aspects of the absence of cytokinesis. a-c. Meiocytes showing the absence of the first cytokinesis in metaphase II (a), anaphase II (b), and telophase II (c). d. Tetranucleated monad. e. Binucleated dyad. f. Binucleated microspore with a micronucleus (arrow). g. Triad with a binucleated micospore. h, i. Telophase II undergoing simultaneous cytokinesis. 
Several genes have been reported to cause a lack of cytokinesis in maize (Beadle, 1932; Miller, 1963; Rhoades and Dempsey, 1966). The absence of cytokinesis has also been recorded in some inbred lines and maize hybrids (Defani-Scoarize et al., 1995a,b, 1996; Caetano-Pereira et al., 1998; Utsunomiya et al., 2002; Pagliarini et al., 2002; Ricci et al., 2007; Silva et al., 2007).

The absence of the first cytokinesis in the hybrid Garra predisposed some meiocytes to the formation of a restitutional nucleus in the second division (Figure 2a-e). The segregated genomes of the first division were rejoined in a single nucleus in prophase II (Figure 3a), and 20 segregated chromosomes could easily be counted in metaphase II (Figure $3 \mathrm{~b}$ ) as well as the 20 segregated chromatids in anaphase II (Figure 3c) and telophase II (Figure 3d). An additional cytological evidence of the formation of a restitution nucleus formation in these meiocytes was provided by the presence of two nucleoli in telophase II (Figure 3e). As a result of this phenomenon, after cytokinesis, a dyad was formed, giving rise to two unreduced microspores (Figure 3f). The absence of the first cytokinesis also predisposed some meiocytes of the hybrids Garra and CD304 to the formation of a tripolar spindle (Figure 3g-i). In some meiocytes, the spindles converged to a single pole (Figure $3 \mathrm{~g}$ ), rejoining the segregated chromatids of anaphase II (Figure 3h). A triad with a restitutional nucleus (Figure 3i) was formed after cytokinesis.

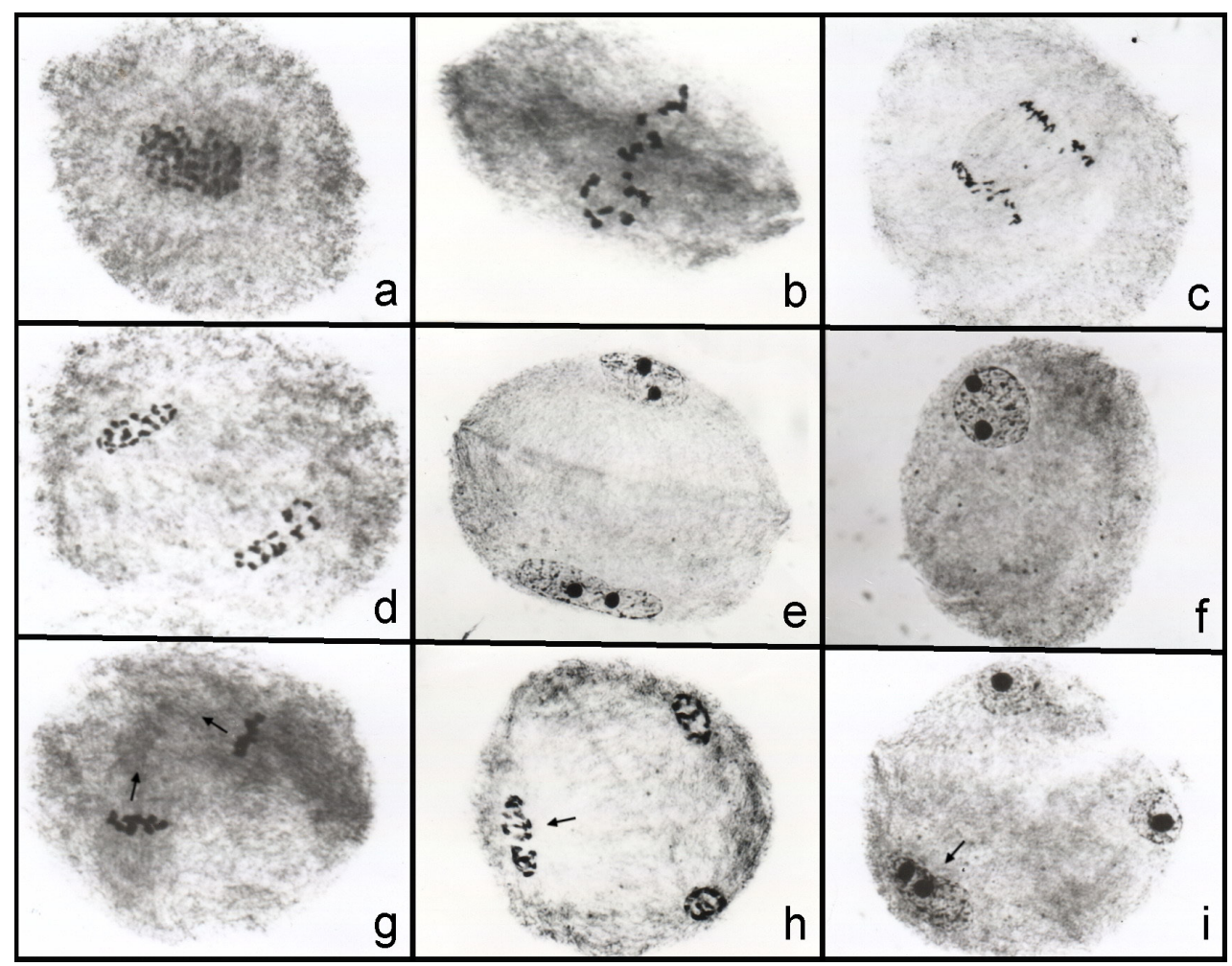

Figure 3. Aspects of restitution nucleus formation in hybrids Garra and CD304. a. Prophase II rejoining the segregated genomes. b. Metaphase II with 20 chromosomes in the metaphase plate. c. Anaphase II with 20 segregated chromatids. d. Early telophase II with 20 chromatids in each nucleus. e. Telophase II with two nucleoli in each restitution nucleus. f. Unreduced microspore with two nucleoli. g. Metaphase II showing tripolar spindles (arrows). h. Telophase II with a restitution nucleus (arrow). i. A triad with an unreduced microspore (arrow). 
Absence of cytokinesis leading to unreduced gamete formation has been widely reported in higher plants (Veillux, 1985; Bretagnolle and Thompson, 1995), and also in maize inbred lines and hybrids (Defani-Scoarize et al., 1995a,b, 1996; Caetano-Pereira et al., 1998; Utsunomiya et al., 2002; Pagliarini et al., 2002; Ricci et al., 2007; Silva et al., 2007). Unreduced gametes have great importance in breeding programs when polyploids are desirable.

The meiotic process is genetically controlled and its harmonious course ensures normal gamete formation. Several meiotic mutants have been reported in maize (Golubovskaya, 1979, 1989; Golubovskaya et al., 1993); they result in complete or partial male sterility. Research conducted with different plant species has shown that seed production is closely related to meiotic stability (Moraes-Fernandes, 1982; Bodanese-Zanettini et al., 1983; Pagliarini, 2000). In this context, Love (1951) suggested that a cereal breeding program could be continuously accompanied by cytological analyses in order to eliminate plants with meiotic instability that could compromise the stability of the future cultivar.

Allogamous plants or hybrids, due to heterozygosis, generally show normal meiosis. However, after selfing, several meiotic abnormalities, mainly those controlled by major genes, emerge in endogamous plants. A high frequency of meiotic abnormalities has been reported in inbred lines of maize (Pagliarini, 1983, 1989; Defani-Scoarize et al., 1995a,b, 1996; Pagliarini et al., 2002). In inbred maize lines with low combining ability, Pagliarini $(1983,1989)$ showed that the chiasma frequency is lower and that several types of meiotic abnormalities are higher. In the present hybrids, the high frequency of meiotic abnormalities was remarkable considering the heterozygosis. It was surprising that some meiotic abnormalities, such as the absence of cytokinesis, occurred in all the genotypes, although at different frequencies. This fact suggests that these hybrids probably have a common genitor. Although the absence of the first cytokinesis was frequent in all the hybrids, its occurrence at the end of meiosis, accompanied by a late second cytokinesis, allowed the formation of a high frequency of normal tetrads. Irregular chromosome segregation and cytomixis can also affect the meiotic product.

The lowest mean frequency of meiotic abnormalities (21.27\%) was found in the hybrid SG6010, whereas the highest (44.43\%), in the hybrid P30K64. However, when comparing the hybrid only in regard to the frequency of abnormal meiotic products considering that some meiotic errors are reversible during the process, the lowest frequency $(7.63 \%)$ was found in CD304 and the highest (43.86\%) in Garra. Thus, considering the percentage of abnormal meiotic products, we suggest that only the hybrids CD304, P30K64, SG6010, and P30F53 remain in the breeding program as sources of inbred lines to create new silage corn hybrids adapted to the South Brazil region.

\section{ACKNOWLEDGMENTS}

Research supported by CNPq/Fundação Araucária (PRONEX).

\section{REFERENCES}

Baker BS, Carpenter AT, Esposito MS, Esposito RE, et al. (1976). The genetic control of meiosis. Annu. Rev. Genet. 10: 53-134.

Beadle GW (1932). A gene in Zea mays for failure of cytokinesis during meiosis. Cytologia 3: 142-155.

Bodanese-Zanettini MH, Moraes-Fernandes MIB and Salzano FM (1983). Genetic and environmental effects on the frequency of meiotic disturbances in wheat. Rev. Bras. Genet. VI: 43-47. 
Bretagnolle F and Thompson JD (1995). Gametes with the somatic chromosome number: mechanisms of their formation and role in the evolution of autopolyploid plants. New Phytol. 129: 1-22.

Caetano-Pereira CM and Pagliarini MS (1997). Cytomixis in maize microsporocytes. Cytologia 62: 351-355.

Caetano-Pereira CM, Scoarize MA, Pagliarini MS and Brasil EM (1998). Syncytes - abnormal cytokinesis and spindle irregularities in maize microsporogenesis (Zea mays L. - meiosis - Brazil). Maydica 43: 235-242.

Defani-Scoarize MA, Pagliarini MS and Aguiar CG (1995a). Causes of partial male sterility in an inbred maize line. Cytologia 60: 311-318.

Defani-Scoarize MA, Pagliarini MS and Aguiar CG (1995b). Evaluation of meiotic behavior in double-cross maize hybrids and their parents. Maydica 40: 319-324.

Defani-Scoarize MA, Pagliarini MS and Aguiar CG (1996). Meiotic behavior of inbred lines of maize (Zea mays L.). Nucleus 39: 10-18.

Golubovskaya IN (1979). Genetic control of meiosis. Int. Rev. Cytol. 58: 247-290.

Golubovskaya IN (1989). Meiosis in maize: mei genes and conception of genetic control of meiosis. Adv. Genet. 26: 149-192.

Golubovskaya I, Grebennikova ZK, Avalkina NA and Sheridan WF (1993). The role of the ameiotic1 gene in the initiation of meiosis and in subsequent meiotic events in maize. Genetics 135: 1151-1166.

Gomes MS, Von Pinho RG, Ramalho MAP, Ferreira DV, et al. (2004). Genetic variability in maize lines for characteristics related to silage yield. Pesq. Agropec. Bras. 39: 879-885.

Gottschalk W and Kaul MLR (1974). The genetic control of microsporogenesis in higher plants. Nucleus 17: 133-166.

Love RM (1951). Varietal differences in meiotic chromosome behavior of Brazilian wheats. Agron. J. 43: 72-76.

Miller OL (1963). Cytological studies in asynaptic maize. Genetics 48: 1445-1466.

Moraes-Fernandes MIB (1982). Estudo da instabilidade meiótica em cultivares de trigo. Efeito genotípico, relação com fertilidade e seleção de plantas estáveis. Pesq. Agropec. Bras. 17: 1177-1191.

Pagliarini MS (1983). Correlação entre freqüência de quiasmas e capacidade de combinação em linhagens autofecundadas de milho (Zea mays L.): uma análise prévia. Rev. Unimar 5: 37-46.

Pagliarini MS (1989). Avaliação da Frequência de Quiasmas em Milho (Zea mays L.) e suas Implicações com a Capacidade de Combinação para a Produção de Grãos. Doctoral thesis, Escola Superior de Agricultura Luiz de Queiroz, Piracicaba.

Pagliarini MS (2000). Meiotic behavior of economically important plant species: the relationship between fertility and male sterility. Genet. Mol. Biol. 23: 997-1002.

Pagliarini MS, Defani MA, Meirelles WF and Pereira JE (2002). Recurrence of multiple meiotic abnormalities in maize genotypes from the same origin and their influence on productivity. Crop Breed. Appl. Biotechnol. 2: 355-360.

Rhoades MM and Dempsey E (1966). Induction of chromosome doubling at meiosis by the elongate gene in maize. Genetics 54: 505-522.

Ricci GC, Silva N, Pagliarini MS and Scapim CA (2007). Microsporogenesis in inbred line of popcorn (Zea mays L.). Genet. Mol. Res. 6: 1013-1018.

Silva MFPTB, Lopes EF, Pagliarini MS and Scapim CA (2007). Effects of endogamy on microsporogenesis in popcorn. Crop Breed. Appl. Biotechnol. 7: 321-326.

Utsunomiya KS, Bione NCP and Pagliarini MS (2002). How many different kinds of meiotic abnormalities could be found in a unique endogamous maize plant? Cytologia 67: 169-176.

Veillux R (1985). Diploid and polyploid gametes in crop plants: mechanisms of formation and utilization in plant breeding. Plant Breed. Rev. 3: 253-288.

Zago CP (1991). Cultura de Sorgo para Produção de Silagem de Alto Valor Nutritivo. In: $4^{\circ}$ Simpósio sobre Nutrição de Bovinos (Peixoto AM, Moura JC and Faria VP, eds.). Fundação de Estudos Agrários “Luiz de Queiroz", Piracicaba, $169-217$. 